\title{
Ink analysis raises storm over Viking map
}

\section{John Whitfield and Rex Dalton}

Scientists are locking horns over a Viking map of America. One group claims to have evidence that the document is a fake, but another says that the parchment on which it is drawn predates Christopher Columbus's 1492 discovery of the New World.

The Vinland Map's ink dates to the twentieth century, argues one team - adding that the parchment's age is irrelevant. But other researchers have roundly criticized the ink analysis, saying that the carbon dating of the parchment nudges researchers closer to the conclusion that the map is genuine.

If it is, then the parchment, which depicts LeifEricsson's journey to what is now Canada in the tenth century $\mathrm{AD}$, is the oldest map of America. It came to light in 1957, when Yale University paid \$1 million for it. The idea that the Vikings made it to America before Columbus was new and controversial at the time, although archaeological findings have since confirmed it.

But some have always doubted the map's authenticity, and in 1974 crystals taken from the map were found to contain anatase, a form of titanium dioxide used in white paint which has only been manufactured since 1923 .

Now chemists Robin Clark and Katherine Brown of University College London have studied the map's ink with a technique called laser Raman microscopy, which uses laser scattering to reveal chemical composition. The map's lines are made of two different substances, they report ${ }^{1}$. Their black centres are carbon; theiryellowish edges are composed of anatase. Clark says that anatase shouldn't be present in a map from the fifteenth century. He thinks that a forger overlaid a yellow line

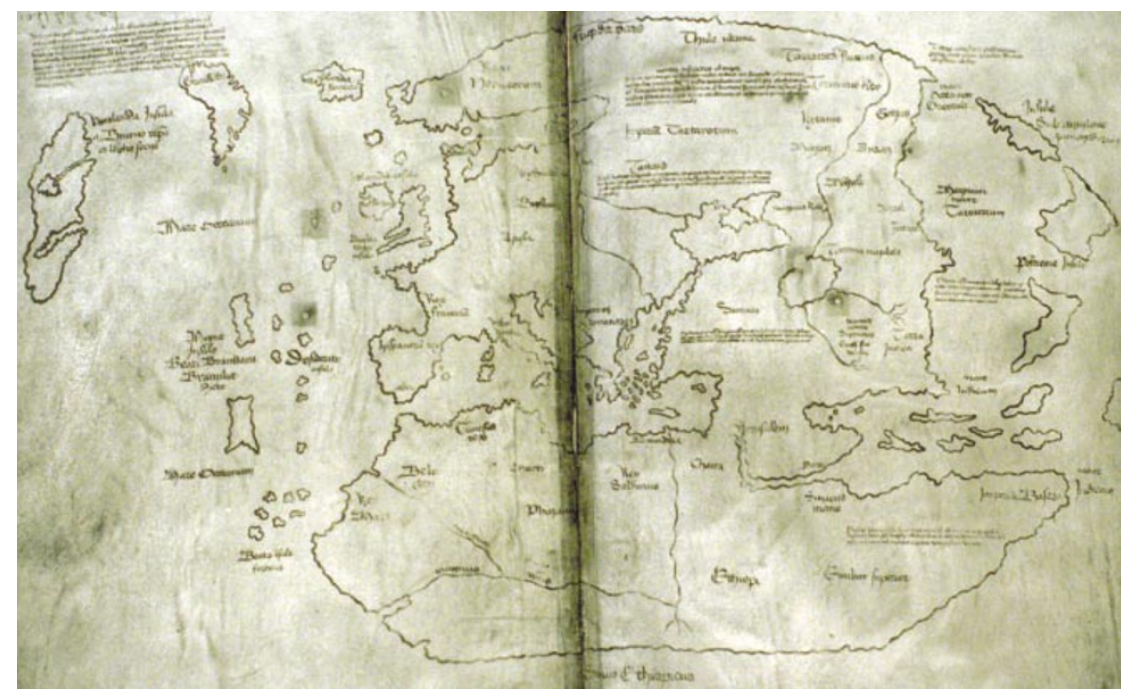

Fact or fake? The Vinland Map's age is still disputed after conflicting analyses of its ink and parchment.

with a black one to create an aged appearance.

But other experts have blasted these conclusions. They are "singularly unconvincing", says physicist Thomas Cahill of the University of California, Davis. "There's no example of any forger trying to do double inking."

Jill Pasteris of Washington University in St Louis, Missouri, a leading authority on laser Raman microscopy, says that the London team has overstated its results, and that the researchers did not even use a microscope to scan the parchment properly for anatase.

"The presence of anatase is by no means conclusive proof that the map is a forgery," says Jacqueline Olin, a retired Smithsonian Institution chemist who has studied the map for 30 years. More analysis is needed to answer the anatase question decisively, she says.

Olin is part of a team led by Garman Harbottle, a specialist in carbon dating at Brookhaven National Laboratory in Upton, New York, that has dated the map's parchment to between 1423 and 1445 (ref. 2).

"It doesn't prove the map's authenticity, but it's another piece of evidence to be put in the scales," says Harbottle. "It sets the bar higher for those who want to show that the map's a fake." Carbon-dating the ink might settle the matter, Harbottle suggests. But current carbon-dating techniques require more material than the ink could provide.

\footnotetext{
Brown, K. L. \& Clark, R. J. H. Anal. Chem. 74,

3658-3661 (2002).

. Donahue, D. J., Olin, J. S. \& Harbottle, G. Radiocarbon 44, 45-52 (2002).
}

\section{Swiss scientists fear for top ranking in basic research}

\section{Oliver Schmidt, Munich}

With generous science funding and worldclass facilities, Switzerland is often seen as a land of milk and honey for researchers. But paradise is in trouble, say scientists working there. Over half of the scientists questioned by the Swiss National Science Foundation (SNSF), the main Swiss research funding agency, fear that the country is losing ground in international competition.

"Our leading position is endangered," agrees Konrad Basler, a molecular biologist who is based at the University of Zurich.

The SNSF's findings come in a report, released on $30 \mathrm{July}$, detailing a survey of 4,000 researchers - around half of Swiss science's workforce. Fears for the status of Swiss research also seem to be backed up by citation statistics for Swiss research papers.
Markus von Ins of the Centre for Science and Technology Studies in Bern says Swiss dominance in the National Science Indicator (NSI) rankings, which measure the average scientific impact of papers produced by a particular country, is waning. Switzerland topped the NSI table from 1981 to 2001, but although its score has improved little since 1981, that of the United States, in second place, has increased by $6 \%$, with Britain and the Netherlands also closing the gap.

Swiss scientists say that the government's short-term economic strategy is partly to blame. Annual funding for Swiss basic research rose modestly from 215 million Swiss francs (US\$146 billion) to 248 million Swiss francs between 1991 and 2001, while funding for applied research tripled to 321 million Swiss francs. "The priorities have clearly switched from fundamental to applied research," says Adriano Aguzzi, a neuropathologist at the University of Zurich.

The SNSF, which already spends most of its money on basic research, has called for a billion Swiss francs in extra funding between 2003 and 2007. The Swiss Science and Technology Council, which advises the government on science-policy issues, has promised to support the SNSF's plea. "We recommend doubling the budget," says Gottfried Schatz, the council's president.

George Thomas, a molecular biologist at the Friedrich Miescher Institute in Basel, says that Switzerland is still an attractive place for research. "Switzerland is but a small country, and the SNSF is doing a good job," he says. "But with massive US investment in the life sciences, it's really difficult to keep on track." 